\title{
ANÁLISE SOCIORRETÓRICA DOS ABSTRACTS DE GRADUANDOS EM FÍSICA E LETRAS-LÍNGUA PORTUGUESA EM EVENTOS CIENTÍFICOS
}

\author{
SOCIORHETORICAL ANALYSIS OF THE ABSTRACTS OF \\ UNDERGRADUANTES IN PHYSICS AND PORTUGUESA LANGUAGE AT A \\ SCIENTIFICS EVENTS
}

Recebido: 11/04/2021

Aprovado: 21/06/2021

Publicado: $30 / 07 / 2021$

DOI: $10.18817 /$ rlj.v5i01.2517

\author{
Kairine Adeline Ribeiro Rodrigues ${ }^{1}$ \\ Orcid ID: https://orcid.org/0000-0003-4650-7440 \\ Ana Paula Rabelo ${ }^{2}$ \\ Orcid ID: https://orcid.org/0000-0003-0616-9985
}

\begin{abstract}
Resumo: Tendo em vista a relevância dos abstracts entre os gêneros acadêmicos de maior circulação na comunidade científica, o presente trabalho ${ }^{3}$ busca analisar, identificar e descrever a organização retórica dos abstracts de graduandos em Física e Letras-Língua Portuguesa. Para a realização das análises tomamos como base os pressupostos teóricos de Swales (1990;2004) em diálogo com MottaRoth e Hendges (1996;2010). O corpus desta pesquisa é formado por 30 resumos científicos aprovados nos anais da VI Semana Universitária da Universidade da Integração Internacional da Lusofonia AfroBrasileira-UNILAB, a SEMUNI, no ano de 2019. O critério de seleção leva em consideração a representatividade no espaço acadêmico, por se tratar de áreas distintas, bem como as suas variáveis relações com o texto. Desse modo,o processo de seleção ocorreu pela busca das palavras Letras e Física no website do evento. Neste sentido, foi realizada uma análise textual propondo verificar os movimentos recorrentes mais utilizados nos cursos. Os resultados demonstram que dentre todos os movimentos, houve uma recorrência alta em descrever a seção que trata da metodologia do trabalho manifestando-se predominantemente em ambas as áreas.
\end{abstract}

Palavras-Chave: Análise Textual. Organização Retórica. Resumo. Língua Portuguesa. Física

ABSTRACT: Considering the relevance of abstracts among the academic genres of greater circulation in the scientific community, the present work seeks to analyze, identify and describe the rhetorical organization of abstracts of undergraduates in Physics and Portuguese Language-Language Arts. In order to carry out the analysis, the theoretical assumptions of Swales $(1990 ; 2004)$ in dialogue with Motta-Roth and Hendges (1996;2010) were used as a basis. The corpus of this research is formed by 30 scientific abstracts approved in the annals of the VI University Week of the University of International Integration of Afro-Brazilian Lusophony-UNILAB, the SEMUNI, in the year 2019. The selection process occurred by searching for the words Letters and Physics on the event's website. In this sense, a textual analysis was performed proposing to verify the recurrent movements most used in the courses. The results show that among all the movements, there was a high recurrence in describing the methodology of the work manifesting itself predominantly in both areas.

Keywords: Textual Analysis. Rhetorical Organization. Abstract.Portuguese Language.Physics

${ }^{1}$ Pós-graduanda em Práticas Pedagógicas pelo Instituto Federal Norte de Minas Gerais (IFNMG) Graduada pela Universidade da Integração Internacional da Lusofonia Afro-Brasileira (UNILAB). Redenção-CE. Membra do grupo de pesquisa Estudos Críticos em Discurso e Sociedade-ATMOS. Email: kairineribeiro@aluno.unilab.edu.br

2 Docente da Universidade da Integração Internacional da Lusofonia Afro-Brasileira (UNILAB). Vice coordenadora do curso de Letras- Língua Portuguesa Redenção-CE. E-mail: anarabelo.p@unilab.edu.br

${ }^{3}$ Este artigo é resultado de uma pesquisa realizada para o Trabalho de Conclusão de Curso (TCC). 


\section{Introdução}

Nos últimos anos, observa-se que os gêneros acadêmicos têm sido objeto de importantes pesquisas científicas no Brasil. O tema vem sendo estudado amplamente por diferentes motivações, e grupos acadêmicos distintos em diversas partes do mundo (dentre eles: BAZERMAN, 2007; CHARAUDEAU, 2004; 2006; FAIRCLOUGH,1999; BAKTHIN, 2011; RODRIGUES, 2001; 2005; ROJO, 2007; SIGNORINI, 2006; SWALES,1990; 2007; MOTTA ROTH, 2005; 2006; BONINI, 2005; HALLIDAY; HASAN, 1985; 1989; MARTIN, 1985; 1989). As diferentes fases dos estudos de gênero e as diversas correntes de pesquisa (MOTTA ROTH, 2008) possibilitaram, consequentemente, aparato teórico para múltiplas análises. O recorte conceitual que fazemos estabelece o diálogo entre os estudos de Swales (1990;2004), Motta-Roth (2008) e Motta-Roth e Hendges (2010).

Neste artigo, analisamos a organização retórica de resumos acadêmicos, tratados corriqueiramente no Brasil na forma em língua inglesa "abstract”. O "abstract” é utilizado como gênero de acesso a eventos científicos, por meio de seu envio para a avaliação em participação em comunicações orais ou mesas-redondas em congressos, simpósios, jornadas (MOTTA-ROTH; HENDGES, 2010). Ele ainda compõe a estrutura retórica de artigos científicos, teses, dissertações e monografias, depois do título e da apresentação dos autores, a parte que introduz a descrição da pesquisa.

Dada a representatividade deste gênero na comunidade acadêmica ${ }^{4}$, faz-se necessário reconhecer que estratégias didáticas precisam ser criadas para que alunos de graduação, em seus primeiros semestres, já possam ter conhecimento da sua existência, e assim promover o incentivo ao hábito da leitura e produção, bem como de manuais, que possam orientar o processo de produção desses gêneros.

Para Swales (1990), utilizamos o nosso repertório de gêneros para nos comunicar, o que os coloca, senão como o central, como um dos elementos centrais da comunicação humana. "Os gêneros são veículos de comunicação para atingir um objetivo" (Swales,1990, p.46). Assim, estando os gêneros acadêmicos como um dos elementos centrais na mediação da comunicação acadêmica, é fundamental que os

4Utilizamos os termos "comunidade acadêmica" e "comunidade discursiva" tal como Motta-Roth (1998, p. 94) "sem definição rígida de seu conceito, mas unicamente para fazer referência às normas e convenções de um grupo em relação ao discurso escrito [...]" 
estudantes dominem o uso daqueles que são mais recorrentes. Porém, compreendemos que outras questões circundam a problemática de seu acesso: a) Por parte dos estudantes: a dificuldade de acadêmicos, que pode envolver uma relação entre o domínio do conteúdo e a inexperiência da escrita do próprio gênero; e; b) Por parte dos docentes: ao apresentar o gênero, seja para leitura ou produção, eles podem, por vezes, orientar de modo superficial, sem atentar para as especificidades de sua produção nas diversas áreas do ensino, resultando em um problema que pode se estender ao longo do percurso da graduação ou mesmo em níveis superiores.

Com base nessa realidade, voltamos nossa atenção aos resumos acadêmicos de graduandos de Letras-Língua Portuguesa e Física que, ao nosso ver, são representativos no espaço acadêmico, por se tratar de áreas cuja relação com o texto ocorre de forma distinta. Por esta razão, foram escolhidos dois institutos: O ILL (Instituto de Linguagens e Literaturas) e o ICEN (Instituto de Ciências Exatas e Natureza), sendo o curso de Letras aquele em que o aluno em formação tem maior contato com procedimentos metodológicos para a leitura e produção dos gêneros e a Física o que tem menor contato. Em outras palavras, o curso de Letras, mais do que - curso de Física, possibilita experiências didáticas que contribuem para a compreensão da organização retórica dos gêneros utilizados pela comunidade acadêmica.

O artigo está organizado em três seções. Iniciamos com uma reflexão sobre o conceito de gênero abstract com base em teóricos da área. Posteriormente, adentrase na proposta teórico-metodológica de Motta-Roth e Hendges da organização retórica do gênero. Por fim, trataremos das análises dos abstracts de cada área disciplinar e seus diferentes comportamentos estruturais, marcadores discursivos, além das considerações finais.

\section{Sobre $o$ gênero acadêmico}

Swales (1990), em seus estudos propôs construir o conceito de gênero partindo de uma investigação em quatro distintas áreas do conhecimento sendo elas: folclore, literatura, linguística e retórica. Baseado nestas investigações, ele fundamenta algumas particularidades para designar um gênero - a classe de eventos comunicativos, os propósitos comunicativos, as variações em sua prototipicidade, a 
lógica e a terminologia. Conforme Swales (1990, p.58), "Um gênero compreende uma classe de eventos comunicativos, cujos membros compartilham um conjunto de propósitos comunicativos".

Segundo Rabelo (2017), há uma diferença entre os gêneros acadêmicos e os gêneros discursivos da academia, sendo o segundo toda a diversidade de gêneros que circula no ambiente acadêmico, dentro e fora da sala de aula. Para a análise do abstract, esse trabalho adota o conceito de gênero acadêmico proposto por Rabelo (2017, p. 211), "como aqueles que são produzidos e que circulam no âmbito universitário como meio de comunicação entre professores e alunos (pesquisadores ou não), com o propósito específico de proporcionar a divulgação científica".

O abstract $^{5}$ é um gênero acadêmico que pode ser encontrado tanto isoladamente em caderno de resumos, anais de eventos, ou compondo textos mais extensos como artigos, monografias, dissertações e teses (MOTTA-ROTH; HENDGES, 2010, p.152). Vale, contudo, ressaltar, que a academia pode exigir dois tipos de resumos: ou simples, com estrutura similar à do abstract, ou expandido, um texto mais longo (que tem um tamanho que oscila entre 7.500 caracteres sem espaços a 15 mil), que visa apresentar mais detalhadamente a metodologia da pesquisa e os resultados alcançados. Desta forma, não é possível a correspondência entre os termos abstract e resumo expandido ${ }^{6}$. Em cada uma dessas ocorrências, há um propósito comunicativo distinto. Assim, antes mesmo de analisar a estrutura retórica do abstract, faz-se necessário pensar sobre o seu propósito comunicativo?

Segundo Pereira e Rodrigues, a análise sociorretórica de gêneros ocorrem enquanto ações que, além de materializar uma classe de eventos e compartilhar propósitos comunicativos, também: “(c) possuem traços específicos prototípicos; (d) apresentam lógica inata, e (e) determinam usos linguísticos (sic) específicos de

\footnotetext{
${ }^{5}$ Motta-Roth e Hendges (1996) intitulam o gênero "abstract" como "resumo acadêmico" seja para resumos em Língua Portuguesa ou Inglesa.

${ }^{6}$ Machado, Silva e Mata (2002) descrevem quatro tipos de resumos: o resumo escolar, o de tese e dissertação, o abstract e o de trabalhos para congressos. As autoras associam os "resumos de trabalhos de congressos" ao que estamos chamando de abstract. Entendemos que o abstract é o resumo simples de congressos, com função retórica similar aos de testes e dissertações, mas diferente daquelas do congresso, por isso não está inserido em textos maiores e mais complexos (cf. MOTTAROTH; HENDGES 2010, p.152).

${ }^{7}$ Segundo Zakir (2013,p.882) apenas de, por muito tempo, ter considerado o propósito comunicativo como o aspecto mais relevante da produção de um gênero, "em artigo escrito com Askehave em 2001,Swales considera que o propósito comunicativo não é tão visível quanto á forma e que, devido a isso, não seria mais critério "básico e fundamental", mas continuaria mantido como um critério privilegiado para o reconhecimento do gênero".
} 
acordo com a comunidade discursiva" (RODRIGUES; PEREIRA, 2009, p. 6). [Grifos nossos].

Das ações sociais materializadas pelo gênero (RODRIGUES; PEREIRA,2009), interessa-nos descrever e analisar apenas duas delas: o propósito comunicativo e os usos de acordo com as necessidades da comunidade discursiva.

E qual o propósito comunicativo do abstract? Ele é um resumo acadêmico/abstract, publicado em anais ou enviado para verificação em periódicos da comunidade acadêmica: uma prévia das pesquisas produzidas ou em desenvolvimento, contemplando uma heterogeneidade de distintos campos. $O$ abstract é um gênero de comunicação e divulgação científica que estabelece relação com o pesquisador, sua prática acadêmica e os diversos campos disciplinares (MENESES,2015; MOTTA- ROTH E HENDGES,2010; BEHLING,2008).

A estrutura retórica aqui apresentada é a de Motta-Roth e Hendges (1996). Em sua proposta, estão descritos cinco movimentos retóricos, conforme quadro a seguir:

Quadro 1 - Descrição retórica do gênero abstract

\begin{tabular}{|l|}
\hline MOVIMENTO 1 - SITUAR A PESQUISA \\
\hline Sub-função 1A - Estabelecer interesse profissional no tópico ou \\
\hline Sub-função 1B - Fazer generalizações no tópico e/ou \\
\hline Sub-função 2A - Citar pesquisas prévias ou \\
\hline Sub-função 2B - Estender pesquisa prévias ou \\
\hline Sub-função 2C - Contra-argumentar pesquisas prévias ou \\
\hline Sub-função 2D - Indicar lacunas em pesquisas prévias \\
\hline MOVIMENTO 2 - APRESENTAR A PESQUISA \\
\hline Sub-função 1A - Indicar as principais características ou \\
\hline Sub-função 1B - Apresentar os principais objetivos e/ou \\
\hline Sub-função 2 - Levantar hipóteses \\
\hline MOVIMENTO 3 - DESCREVER A METODOLOGIA \\
\hline MOVIMENTO 4 - SUMARIZAR OS RESULTADOS \\
\hline MOVIMENTO 5 - DISCUTIR A PESQUISA \\
\hline Sub-função 1 - Elaborar conclusões e/ou \\
Sub-função 2 - Recomendar futuras aplicações \\
\hline
\end{tabular}

Fonte: Motta-Roth e Hendges (1996, p. 68).

A proposta das autoras sistematiza, no nosso entendimento, os movimentos de modo a: a) contextualizar a pesquisa na área, com recorte temporal e esclarecimentos sobre a contribuição à academia e/ ou sociedade; b) apresentar problema/objetivo/hipóteses; c) descrever a metodologia; d) apresentar resultados e; e) conclusões, considerações, comentários, baseada na proposta de Bittencourt (1995). Isso implica dizer que a estrutura proposta não suporta a inserção de um breve detalhamento do suporte teórico utilizado para a pesquisa, mostrando na nossa 
avaliação que se ocorrer a menção aos textos base, tende ocorrer como uma informação secundária, inserida no MOVIMENTO 1/ Sub-função 2A.

A mesma compreensão - do suporte teórico como elemento secundário aparece no trabalho desenvolvido por André Japiassu (2013), do Instituto Fio Cruz, quando apresenta uma descrição da estrutura de resumos da área de saúde, quanto em Ferreira (2011) baseada em:

Problema: O resumo é um dos gêneros mais solicitados na academia, apresentando-se em dois tipos: síntese e planejamento de trabalho acadêmico. Objetivo: A partir dessa constatação, objetivamos com este trabalho comparar os dois tipos do gênero. Método: os fundamentos teóricos apoiam se em Bronckart (1997), Guimarães Silva e Da Mata (2002), Machado (2004 e 2010), Medeiros (2003), Motta-Roth e Hendges (2010). A metodologia de base qualitativa segue os procedimentos dos trabalhos documentais de comparação. Resultados: Os resultados apontam que os resumos, embora apresentem semelhanças, exibem diferenças relevantes, em relação a situação de produção, objetivo, posicionamento dos interlocutores, entre outras. Conclusão: Consideramos importante ensinar esse gênero no ensino superior, focalizando as funções desses dois tipos de resumo. (FERREIRA,2011, p.61).

Essa questão conflita com as orientações dadas pelos diferentes congressos, que muitas vezes incluem referencial teórico como um dos movimentos exigidos para a aprovação do trabalho no congresso.

Subordinados a normas acadêmico-científicas, frequentemente explicitadas, por exemplo, nas normas de apresentação de resumos de diferentes congressos, em que se pede que os resumos apresentem os objetivos, os pressupostos teóricos, a metodologia, os resultados e as conclusões a que se chegou (MACHADO,2010,P.160). [grifos nossos]

Apesar de reconhecer a presença desse movimento como traço presente no gênero, seja na orientação para a sua escrita, seja na sua realização, adotaremos a proposta de organização retórica de Motta-Roth e Hendges (2010), na qual ele ocupa um papel secundário (ver Quadro 1).

\section{A organização retórica do gênero Abstract proposto por Motta-Roth e Hendges}

Motta-Roth e Hendges (1998; 2010) e Motta-Roth (1996) propuseram movimentos e subfunções retóricas com objetivos pedagógicos similares à proposta teórica de Swales. As contribuições teóricas desse autor foram de grande relevância 
para a consolidação da proposta de ensino English for Specific Purposes- ESP que visa proporcionar os estudantes a praticar e reconhecer o gênero, adquirindo uma consciência retórica no momento em que se apropriam deste gênero estudado. A sociorretórica de Swales (1990) está focada "na organização retórica dos tipos de textos, definidos por suas propriedades formais bem como por seus objetivos comunicativos dentro de contextos sociais" (Hyon 1996: 695 apud RABELO, 2017, p. 109). Inicialmente, os estudos eram voltados para a Língua Inglesa, em seguida, Swales ampliou suas investigações para 48 introduções de artigos de pesquisas, alonga para 110, em diferentes áreas disciplinares, Psicologia, Educação,Física. Apartir desses estudos, elabora o Modelo CARS (Create a research space) ao qual estabelece um suporte para a análise sociorretórica dos gêneros acadêmicos, contribuindo para um percurso metodológico, com contribuições para desenvolvimento de inúmeras pesquisas. Dessa forma, resulta nas análises da organização retóricas dos gêneros que tratam da organização estrutural, em outras palavras, dos movimentos ou passos retóricos utilizados pelas comunidades para alcançar seus propósitos comunicativos.

As pesquisadoras apresentaram um trabalho acerca do estudo de gêneros acadêmicos, no qual elencam alguns aspectos de categorização da estrutura retórica para o gênero abstract. Em pesquisa datada de 1996, propuseram-se a analisar um corpus composto por três grupos de vinte abstracts coletados de revistas científicas "publicadas entre os anos 1989 e 1995" (MOTTA-ROTH; HENDGES,1998, p.117). Os dados resultaram numa reavaliação das propostas de organização retórica do resumo/abstract a partir de Bittencourt (1995;1996). Essa reformulação resultou, dentre outros aspectos, na alteração do termo "passos" (SWALES,1990) por "subfunções", como demonstrado no Quadro 1.

Associados aos cinco movimentos retóricos (MOTTA-ROTH; HENDGES,2010) que dizem respeito à construção do abstract podem ocorrer as subfunções nos movimentos 1,2,5, (ver Quadro 1) na ordem apresentada ou em outras ordens, inclusive com exclusão de algumas delas, decisões que dependem da área e do propósito comunicativo. Enquanto os "movimentos" estabelecem os níveis informacionais mais abrangentes e as "subfunções" trazem dados mais específicos, permitindo a compreensão da organização retórica do gênero. Para Motta-Roth e Hendges o "movimento [retórico]" pode ser entendido como: 
Um bloco de texto que pode se estender por mais de uma sentença, realizando uma função comunicativa específica (p.ex., em artigos científicos, estabelecer o território epistemológico da área), e que, juntamente com outros movimentos, constitui a totalidade da estrutura informacional que deve estar presente no texto para que esse possa ser reconhecido como um exemplar de um dado gênero do discurso (MOTTA-ROTH;HENDGES,1998,p.127).

A proposta da estrutura retórica de Motta-Roth e Hendges (2010) para os abstracts é baseada num estudo anterior de Bittencourt (1995;1996). O Quadro 1 é uma reformulação adaptando aos resultados alcançados com sua pesquisa. Vale ressaltar que, para Bittencourt (1995;1996), a escrita dos abstracts é realizada já com intenção de provocar curiosidade no leitor sobre a pesquisa, pois potencialmente podem atrair à leitura.

\section{Procedimentos metodológicos}

$\mathrm{Na}$ busca de tentar responder as questões, dividimos a pesquisa em dois momentos somente para critério de descrição, estão apresentados na seguinte ordem:

a) Análise contextual da produção dos gêneros a partir dos estudos das ementas das disciplinas (Leitura e produção textual I, Leitura e produção de texto II, TCC I e Introdução ao pensamento científico).

b) Análise da estrutura retórica dos gêneros, a partir do Quadro 1.

O corpus utilizado neste caso, refere-se aos objetos de análise dos dados que são formados por 30 amostras do gênero abstracts em duas disciplinas distintas 15 na área das ciências da natureza (Física) e 15 ciências humanas (Letras - Língua Portuguesa), publicadas em Anais da VI Semana Universitária da Unilab, no Ceará, no período de outubro de 2019, na plataforma do evento científico.

Inicialmente, para a análise das produções acadêmicas tomamos como parâmetro a organização retórica de Motta-Roth e Hendges (2010) acerca dos abstracts, juntamente com as pistas léxico-gramaticais que categorizam as informações no texto. Dito isso, relembramos que a análise destas amostras é atribuída pelos movimentos utilizados, sendo identificados com a sigla AF (Abstract Física) e numeradas de 1 a 15 AF1, AF2, AF3, etc. Assim como as 15 produções de Língua Portuguesa ALP1, ALP2, ALP3, etc.

Apesar de caracterizados em áreas distintas, Linguística e Literatura, os resumos coletados do curso de Língua Portuguesa não serão separados em 
subgrupos, uma vez que o grupo não faz distinção de suas áreas. Em seguida, descrevemos os diferentes comportamentos estruturais e identificamos um modelo de distribuição do conteúdo dos abstracts na área de Física e Letras- Português.

\section{Análise das ementas}

Para apresentação das ementas das disciplinas ministradas nos dois cursos, criamos dois quadros: o primeiro com as disciplinas do núcleo comum ofertadas pelo curso de Letras e o segundo que trata sobre as disciplinas de metodologia comum a aos dois cursos, como apresentado a seguir.

Quadro 2 - Disciplinas de Língua Portuguesa, do núcleo comum da Unilab, sobre gêneros acadêmicos

\begin{tabular}{|c|c|c|}
\hline $\begin{array}{l}\text { Componente } \\
\text { Curricular }\end{array}$ & Língua Portuguesa & Física \\
\hline $\begin{array}{ll}\text { 1. LPT I } & \text { LPT } \\
\text { Leitura } & \text { e } \\
\text { Produção } & \text { de } \\
\text { Texto I } & \end{array}$ & $\begin{array}{l}\text { Gêneros acadêmicos (leitura e } \\
\text { escrita na perspectiva da } \\
\text { metodologia científica e da análise } \\
\text { de gêneros): } \\
\text { Esquema; Fichamento; Resenha; } \\
\text { Resumo (síntese por extenso); } \\
\text { Memorial; Seminário; Normas da } \\
\text { ABNT }\end{array}$ & $\begin{array}{l}\text { Gêneros acadêmicos (leitura e escrita na } \\
\text { perspectiva da metodologia científica e da } \\
\text { análise de gêneros): } \\
\text { Esquema; Fichamento; Resenha; Resumo } \\
\text { (síntese por extenso); Memorial; } \\
\text { Seminário; Normas da ABNT }\end{array}$ \\
\hline $\begin{array}{lll}2 . \quad \text { LPT } & \text { II } \\
\text { Leitura } & & \text { e } \\
\text { Produção } & \text { de } \\
\text { Texto I } & \end{array}$ & $\begin{array}{l}\text { Gêneros acadêmicos (leitura e } \\
\text { escrita na perspectiva da } \\
\text { metodologia científica e da análise } \\
\text { de gêneros): } \\
\text { Projeto de pesquisa; } \\
\text { Resumo(abstract); Monografia; } \\
\text { Artigo; Livro ou capítulo de livro; } \\
\text { Ensaio; Relatório; Relato de } \\
\text { experiência; Produção audiovisual } \\
\text { etc. }\end{array}$ & $\begin{array}{l}\text { Gêneros acadêmicos (leitura e escrita na } \\
\text { perspectiva da metodologia científica e da } \\
\text { análise de gêneros): } \\
\text { Projeto de pesquisa; Resumo(abstract); } \\
\text { Monografia; Artigo } \\
\text { Livro ou capítulo de livro; Ensaio; } \\
\text { Relatório; Relato de experiência; } \\
\text { Produção audiovisual etc. }\end{array}$ \\
\hline
\end{tabular}

Fonte: Elaborada pelas autoras, com base nos PPCs dos cursos de graduação da Universidade da Integração Internacional da Lusofonia Afro-Brasileira (UNILAB).

Seguimos com a tabela relacionada às disciplinas de metodologia.

Quadro 3 - Disciplinas de metodologia com os respectivos conteúdos científicos de estudo acerca dos gêneros acadêmicos da Unilab

\begin{tabular}{|l|l|l|}
\hline $\begin{array}{l}\text { Componente } \\
\text { Curricular }\end{array}$ & Língua Portuguesa & Fíca \\
\hline
\end{tabular}




\begin{tabular}{|c|c|c|}
\hline $\begin{array}{l}\text { 3.Introdução ao } \\
\text { pensamento } \\
\text { científico: } \\
\text { Problematizações } \\
\text { Epistemológicas }\end{array}$ & $\begin{array}{l}\text { A especificidade do conhecimento } \\
\text { científico. Introdução r a } \\
\text { pensamento histórico- filosófico } \\
\text { relacionado à ciência. Origens do } \\
\text { conhecimento, epistemologia e } \\
\text { paradigmas científicos. A barreira } \\
\text { científica e a representação do } \\
\text { outro. O silenciamento da história e } \\
\text { do protagonismo do Outro: } \\
\text { bárbaros, asiáticos, africanos, } \\
\text { americanos. Sulbaltern Studies. } \\
\text { Novas episteme da da } \\
\text { ciência:visibilidade, } \\
\text { problematização e conceitualização } \\
\text { em pesquisas interdisciplinares do } \\
\text { Lusotropicalismo à lusofonia. }\end{array}$ & $\begin{array}{l}\text { A especificidade do conhecimento } \\
\text { científico. Introdução ao pensamento } \\
\text { histórico- filosófico relacionado à ciência. } \\
\text { Origens do conhecimento, epistemologia } \\
\text { e paradigmas científicos. A barreira } \\
\text { científica e a representação do outro. O } \\
\text { silenciamento da história e do } \\
\text { protagonismo do } \\
\text { Outro: bárbaros, asiáticos, africanos, } \\
\text { americanos. Sulbaltern Studies. Novas } \\
\text { episteme da ciência:visibilidade, } \\
\text { problematização e conceitualização em } \\
\text { pesquisas interdisciplinares do } \\
\text { Lusotropicalismo à lusofonia. }\end{array}$ \\
\hline 4.TCC I & $\begin{array}{l}\text { Elaboração do projeto de pesquisas } \\
\text { referente ao Trabalho de Conclusão } \\
\text { de curso (tema e delimitação, } \\
\text { justificativa, objetivos, problemas e } \\
\text { hipóteses, metodologia referenciais } \\
\text { teóricos). Normas da Associação } \\
\text { Brasileira de Normas Técnicas } \\
\text { (ABNT) }\end{array}$ & $\begin{array}{l}\text { Elaboração do projeto de pesquisa } \\
\text { referente ao trabalho de } \\
\text { Conclusão de curso (tema e delimitação, } \\
\text { justificativa, objetivos, problemas e } \\
\text { hipóteses, metodologia referenciais } \\
\text { teóricos). Normas da Associação } \\
\text { Brasileira de Normas Técnicas (ABNT) }\end{array}$ \\
\hline
\end{tabular}

Fonte: Elaborada pelas autoras, com base nos PPCs dos cursos de graduação da Universidade da Integração Internacional da Lusofonia Afro-Brasileira (UNILAB).

As disciplinas apresentadas no Quadro 2 - LPTI, LPT II, Introdução ao Pensamento Científico e TCC I Quadro 3 - são disciplinas ofertadas em todos os cursos de graduação presencial da Unilab. As três primeiras fazem parte de uma formação básica para que os alunos graduandos possam perceber as especificidades do conhecimento científico e respeitar a complexidade dos diálogos epistemológicos nas diversas culturas. É possível observar que ocorrem formas generalistas para as disciplinas que buscam propiciar a avaliação e não a didatização, dispensando as especificidades de cada área disciplinar, como se essas orientações conseguissem abarcar satisfatoriamente a produção dos gêneros. Para além de conhecer e aprender a formatar textos acadêmicos é necessário dar atenção às metodologias científicas que propiciam distintas maneiras para que os estudantes possam produzir diferentes e variados gêneros com os quais irão se confrontar ao longo da graduação.

O estudo demonstra que, apesar da proposta do currículo inserir a possível experiência dos estudantes com os gêneros, faz-se necessário investigar em que medida essa aprendizagem está dialogando com a realidade dos estudantes. Essa pesquisa não amplia os dados para a aplicação de questionário, mas reconhece que há um campo a ser explorado. 


\subsection{Análise dos abstracts: ocorrência dos movimentos retóricos em Física e Língua Portuguesa}

Como dito, anteriormente, buscamos por meio das categorias expressas acima no Quadro 1, realizar as análises dos abstracts publicizados nos anais de um evento científico, nas áreas de ciências humanas e da natureza. Os abstracts coletados foram produzidos por alunos da Unilab, dos campi do Ceará. Dito isso, efetuamos a análise com base na compreensão do modelo de Motta-Roth e Hendges (1996). No Quadro 3 , temos a síntese das ocorrências retóricas dos 30 abstracts, representadas por AF, graduandos de Física e ALP Língua Portuguesa.

Quadro 3 - Análises percentual das ocorrências dos cinco movimentos retóricos

\begin{tabular}{|l|l|l|}
\hline MOVIMENTO 1- SITUAR A PESQUISA & AF & ALP \\
\hline Subfunção 1A- Estabelecer interesse profissional no tópico e/ou & - & - \\
\hline Subfunção 1B-Fazer generalizaçães no tópico e/ou & $67 \%$ & $47 \%$ \\
\hline Subfunção 2A-Citar pesquisas prévias ou e/ou & - & - \\
\hline Subfunção 2B- Estender pesquisa prévias ou & - & - \\
\hline Subfunção 2C-Contra-argumentar pesquisas prévias ou & - & - \\
\hline Subfunção 2D- Indicar lacunas em pesquisas prévias & - & - \\
\hline MOVIMENTO 2- APRESENTAR A PESQUISA & & \\
\hline Subfunção 1A-Indicar as principais caraterísticas ou e/ou & $7 \%$ & $20 \%$ \\
\hline Subfunção 1B-Apresentar os principais objetivos e/ou & $73 \%$ & $47 \%$ \\
\hline Subfunção 2-Levantar hipóteses & - & $33 \%$ \\
\hline MOVIMENTO 3- DESCREVER A METODOLOGIA & $93 \%$ & $87 \%$ \\
\hline MOVIMENTO 4- SUMARIZAR OS RESULTADOS & $87 \%$ & $33 \%$ \\
\hline MOVIMENTO 5- DISCUTIR A PESQUISA & & \\
\hline Subfunção 1-Elaborar conclusões e/ou & $27 \%$ & $33 \%$ \\
\hline Subfunção 2-Recomendar futuras aplicações e/ou & - & - \\
\hline
\end{tabular}

Fonte: Elaborado pela autora, com base nos movimentos retóricos Motta-Roth e Hendges (1996,p.68).

Tanto no curso de Letras quanto no curso de Física, no movimento retórico "situar a pesquisa", apenas a sub-função 1B - Fazer generalizações do tópico teve ocorrência de realização, não sendo uma preocupação dos estudantes realizar uma contextualização da pesquisa na área em que se insere. A hipótese seria que estariam mais preocupados com a descrição da realização da pesquisa em si, contudo a "subfunção $1 \mathrm{~A}$ - indicar as principais características", do movimento retórico 2 - Apresentar a pesquisa, só foi contemplada por $7 \%$ dos alunos de Física e $20 \%$ dos de Letras. Também foram baixos os resultados dos movimentos 4 e 5 do curso de Letras. 


\subsection{Os diferentes comportamentos estruturais do abstract}

Nesta seção, buscamos descrever o modelo de organização retórica acerca dos movimentos e subfunções dos abstracts realizados pelos autores na VI Semana Universitária, que constitui nosso corpus de pesquisa. As análises estão fundamentadas no modelo proposto por Motta-Roth e Hendges(1996), (ver Quadro 1).

\subsubsection{Movimento 1- Situar a pesquisa}

O Movimento 1- Situar a pesquisa é constituído por seis subfunções (ver Quadro 1). Dentro dessa organização Motta Roth e Hendges (1996, p.68) adaptam o termo "passo" utilizado por Swales(1990), que nomeia as unidades retóricas menores, empregando o termo "subfunção". A função retórica de situar a pesquisa apresenta um procedimento capaz de demonstrar qual a área de estudo que vai ser abordada, e que se insere a pesquisa situando o leitor.

No que se refere, às subfunções 1A e 1B [Mov 1], de acordo com Motta- Roth e Hendges (2010, p.94), remete a pesquisas relacionadas à área, para” chamar a atenção para a relevância de nosso tópico como forma de seduzir leitores em potencial". Como podemos apontar para o excerto deste trabalho:

[ALP 13] "A prática da avaliação da aprendizagem é uma temática que vem ganhando notoriedade da sociedade, dos pesquisadores e acadêmicos."

Constatamos que, dentre os trabalhos analisados, os graduandos que utilizaram a subfunção 1B. Em nossas análises, esta subfunção apresentou uma recorrência de $67 \%$ em AF e $47 \%$ em ALP. Observamos que no momento de fazer as generalizações, os graduandos buscam utilizar mais justificativas de ordem social que acadêmica para fundamentar o seu trabalho. Esta subfunção pode ser visualizada no trecho a seguir:

[AF 1] "Tendo em vista o baixo interesse de jovens pela Física combinado com a carência de novas metodologias para se ensinar essa Ciência, foi desenvolvido o projeto FísicAstro."

No que diz respeito às subfunções $2 \mathrm{~A}, 2 \mathrm{~B}, 2 \mathrm{C}, 2 \mathrm{D}$ elas estão relacionadas a requisitos mais específicos, alicerçadas em pesquisas prévias atribuindo ao 
pesquisador a inserção de citações, estudos, lacunas relacionados à temática (ver Quadro 1). Conforme relatado no Quadro 3 estas subfunções encontram-se ausentes nos trabalhos investigados em ambas as disciplinas.

\subsubsection{Movimento 2 - Apresentar a pesquisa}

O movimento 2 - Apresentar a pesquisa consiste em três subfunções 1A, 1B, 2 (ver quadro 1). A subfunção $1 \mathrm{~A}$ estabelece uma recorrência pequena de $7 \%$ em AF e ALP 20\%. De acordo com Motta Roth e Hendges (1996) esta subfunção indica as principais características da pesquisa. Entretanto, nos trabalhos analisados ela aparece apenas com um tom afirmativo, de modo predominante narrativo empregado para resumir o que o trabalho apresenta. Como podemos ver no exemplo abaixo:

[AF10] "breve descrição das atividades realizadas por estudantes ..."

[AL10] "apresentar aos alunos da escola as literaturas africanas de língua portuguesa especialmente de Angola, Guiné-Bissau e de Moçambique que fazem parte de CPLP."

Em relação a subfunção $1 \mathrm{~B}$ apresenta os principais objetivos da pesquisa visando informar ao leitor os propósitos do trabalho. A ocorrência desta subfunção apresenta $73 \%$ em ALP e $47 \%$ AF notamos em nossas análises que os autores explicam as particularidades do seu trabalho por meio de algumas pistas linguísticas, e marcadores discursivos propostos Motta-Roth e Hendges (1996) em suas pesquisas que nos ajudaram na identificação da subfunção. Vejamos, a seguir os exemplos:

[ALP1] "Para a realização desse estudo, estabelecemos como objetivo geral a análise do contexto contemporâneo do ensino de língua portuguesa em Angola, mais especificamente na província do Namibe".

A ocorrência da subfunção 2 [mov 2] refere-se a levantar hipóteses, isto é, são suposições de caráter científico que podem ser verificáveis ao longo do trabalho, é como uma possível resposta para a pesquisa. Em nossas análises, houve uma baixa recorrência, aparecendo em 33\%, do corpus e somente nos abstracts de Língua Portuguesa. Diante desse resultado, isso pode ocorrer pelo tipo de pesquisa realizada, uma vez que pesquisas qualitativas não exigem hipóteses.Como pode ser observado no exemplo abaixo: 
[ALP1] "A fim de realizar esse estudo, partimos da hipótese de que a norma linguística que fundamenta os livros didáticos angolanos é a portuguesa, ou seja, a variedade europeia do idioma".

Segundo Bhatia (2004) os gêneros demonstram sensibilidade às variações disciplinares, compreendendo desta maneira que a sua circulação, produção e consumo envolvem diferentes práticas, crenças, métodos e interações envolvendo distintas áreas disciplinares.

\subsubsection{Movimento 3 - Descrever a metodologia}

O movimento 3- Descrever a metodologia aparece em 93\% em AF, e ALP $87 \%$ apresentando uma recorrência ampla (ver Quadro 3). Neste caso, os métodos utilizados pelos autores contemplam os questionários, entrevistas, preenchendo as lacunas de como ocorreram os procedimentos e análises dos trabalhos. A presença desse movimento pode ser observada nos seguintes trechos:

[AF3] "Os questionários foram aplicados em 4 alunos do $1^{\circ}$ ano do Ensino Médio, 13 alunos do $2^{\circ}$ ano e 19 alunos do $3^{\circ}$ ano".

[ALP2] "Vale ressaltar que, metodologicamente, o trabalho por sua natureza segue preceitos de uma pesquisa descritiva, da revisão bibliográfica de uma abordagem qualitativa".

No movimento 3, por sua vez, acontecem as escolhas metodológicas que amparam o corpus da pesquisa, com informações procedimentais. Tornando-se facilmente identificada por meio do conteúdo que remete a aspectos metodológicos, e mediante a menção que o autor apresenta as técnicas/ instrumentos de pesquisa "os questionários" utilizados na pesquisa no excerto em AF3.

No trecho de ALP2, é possível visualizar este movimento similarmente ao anterior, por meio da convenção estabelecida através da classificação nos níveis de aprofundamento da pesquisa "descritiva", delineamentos da pesquisa "revisão bibliográfica”, e a própria natureza da pesquisa a "abordagem qualitativa”.

Em conformidade com o que Motta-Roth e Hendges (2010, p. 115), assinalam em relação a função retórica da seção de Metodologia, percebemos que os autores buscam "narrar os procedimentos de coleta e análise dos dados e descrever os materiais que levam à obtenção de resultados, com maior ou menor detalhamento, dependendo do objeto de estudo". Desse modo, essas adequações analisadas nos 
excertos demonstram que estes procedimentos validam a construção do texto e asseguram a integridade dos critérios de amostragem e informações procedimentais de uma pesquisa acadêmica.

\subsubsection{Movimento 4- Sumarizar os resultados}

O movimento 4 - Sumarizar os resultados, nas análises é possível observar que ocorrem a apresentação dos dados com interpretação e comentários. Este movimento esteve presente com uma tendência maior, de $87 \%$, em AF e menor, apenas 33\%, em ALP. Compreendemos que novas pesquisas são necessárias para entender a omissão dos dados parciais das pesquisas realizadas pelos estudantes de Letras.

Quando explicitados, os dados são indicados por meio das pistas gramaticais, como por exemplo "os resultados" que introduz de forma explícita esse movimento.

\footnotetext{
[AF9] "A partir desta pesquisa, percebe-se que a adaptação do dispositivo Cartel pode contribuir significamente para o avanço da educação e produção científica, podendo ser adaptado para qualquer área do conhecimento".

[ALP5] "Os resultados revelaram que o pretérito imperfeito na função de futuro do pretérito tem maior frequência de uso associada a forma verbal perifrástica e a falantes do sexo masculino".
}

As autoras Motta-Roth e Hendges (2010, p.30) afirmam que, "depois de explicar os resultados de seu estudo, você poderá avaliá-los, indicando em que medida são significativos e quais são as consequências para a área em que seu estudo se insere".

\subsubsection{Movimento 5- Discutir a pesquisa}

Por fim, temos o movimento 5 - Discutir a pesquisa, partindo inicialmente da baixa ocorrência encontrada na seção, identificamos que a subfunção 1 está representada em $27 \%$ em AF e ALP 33\%. Muitos dos trabalhos apresentados são pesquisas em andamento e há a hipótese dos estudantes não apresentarem resultados parciais e considerações sobre eles pelo fato das pesquisas ainda não terem sido concluídas.

Diante das análises foi possível identificar que os autores apresentam marcas léxico-gramaticais que foram identificadas por meio do conteúdo que ajudaram na identificação da estratégia retórica, tais como "conclui-se" em ambas as áreas, 
direcionado para a elaboração das conclusões alcançadas com o trabalho. Esta subfunção pode ser visualizada nos trechos a seguir:

[AF15] "Conclui-se que a quantidade de professores que são formados em Licenciatura em Física é bem pequena [...]".

[ALP2] "Conclui-se que, a situação das instabilidades políticas são também alguns fatores que impedem o melhor funcionamento do sistema educativo guineense".

Para Motta-Roth (2010, p.159) algumas características comuns do abstract são os " verbos no pretérito composto e presente do indicativo,terceira pessoa do singular, voz passiva, sentenças declarativas, linguagem econômica com sentenças simples".

Diante destes dados coletados, buscamos analisar, primeiramente, a organização da estrutura retórica dos resumos. Nos deparamos com abstracts heterogêneos e de múltiplos aspectos socioculturais. Em geral, incluíam o padrão descritivo proposto pelas autoras, com os cinco movimentos apresentados, somente o movimento 2-apresentou três subfunções em ALP, e duas subfunções em AF, os demais permaneceram somente com uma subfunção para cada movimento. Dos 30 abstracts analisados, três movimentos tiveram ocorrências de percentuais maiores. Predominantemente em AF, o movimento 3 com 93\%. Em seguida, 87\% o movimento 4.E por último, com 73\% o movimento 2 com um percentual mais baixo comparado aos demais. Em ALP, o movimento 3 apresenta um percentual mais alto, depois os movimentos 1,2 apresentaram $47 \%$ e o movimento 4 aparece com $33 \%$.

A partir das informações encontradas percebemos que ocorre uma variedade disciplinar significativa entre elas, por essa razão torna-se essencial manifestar-se contra a ideia de que a escrita acadêmica se resume a receitas prescritivas, e como vimos como o nosso estudo, elas sofrem alterações independente da área disciplinar. Segundo Motta-Roth e Hendges (1996) o que não ocasiona a descaracterização do gênero, ao contrário corrobora com a ideia de que os movimentos e suas respectivas subfunções podem acontecer em ordens não lineares, bem como podem aparecer e reaparecer ao longo do texto. De acordo com Hyland (2000) os gêneros são construídos de acordo com características próprias de cada comunidade, bem como seus aspectos discursivos, partindo da ideia de os diversos campos disciplinares constroem os gêneros de maneira distinta com suas funções, propósitos comunicativos, crenças e valores. 
Podemos perceber que, ao construir os abstracts, os autores dos trabalhos focaram, em sua maioria, em tratar da metodologia [mov 3], como um movimento mais relevante para selecionar e apresentar nos resumos, ambos os cursos tiverem os maiores percentuais. Com base neste resultado evidenciamos que esta seção retórica estabelece para a comunidade um propósito comunicativo indispensável, uma vez que indica de maneira minuciosa e detalhada os procedimentos e instrumentos aplicados em suas pesquisas científicas.

\section{Considerações Finais}

Este trabalho teve como objetivo apenas a análise das produções científicas de Língua Portuguesa e Física - publicados nos anais da Semana Universitária da Unilab (SEMUNI), um evento acadêmico -, identificando e descrevendo os movimentos retóricos recorrentes no corpus da análise, descobrindo como os graduandos elaboram retoricamente seus resumos a partir das normas do evento.

Observamos que ocorrem omissão de movimentos retóricos mesmo quando solicitados pelas normas do evento e que em nenhum trabalho foram utilizados os movimentos e subfunções em sua totalidade, demonstrando que nem todos são obrigatórios na escrita, e apresenta ordens não lineares. Identificamos pouca presença da organização retórica por parte dos estudantes na escrita. O que revela que a abordagem sociorretórica exige um conhecimento mais amplo, e complexo não voltada para generalizações normativas. Em outras palavras, apesar da organização retórica ser escolhida como um meio mais didático para a relação ensinoaprendizagem dos gêneros, não pode ser entendida como uma fórmula, uma prescrição. Os gêneros são maleáveis, e para produzir um gênero não necessitamos apenas de seguir normas, porém percebemos que diferentes áreas possuem seu modo de agir, de construir os gêneros acadêmicos, dentro do seu campo, com utilização da sua competência linguística, empregando verbos específicos, ou semelhantes.

No decorrer das análises percebemos a presença dos quatro movimentos: Movimento 1 (situar a pesquisa), Movimento 2 (apresentar a pesquisa), Movimento 3 (descrever a metodologia), Movimento 4 (sumarizar os resultados). Dentre estes movimentos o que apresentou maior recorrência foi o movimento III e média I, II, IV, baixa recorrência IV, II.A presença do movimento de metodologia aponta que os 
autores a compreendem como importantes dentro do trabalho acadêmico. Em Língua Portuguesa, o movimento II apresentou uma média, em Física o mesmo movimento teve uma menor correspondência, assim como no movimento IV uma ocorrência média em Física e uma menor recorrência em Língua Portuguesa indicando que os movimentos selecionados pelos graduandos ocorreram a partir do seu modo de interpretar, ordenar e produzir os gêneros acadêmicos.

Essa pesquisa se propõe a contribuir para a reflexão sobre o ensino de gêneros acadêmicos em instituições de ensino superior, bem como na sua produção escrita por meio de reflexões sobre o necessário acompanhamento do processo de produção do aluno por parte do docente. Para que os alunos dos primeiros semestres entendam e vivam o texto acadêmico em sua totalidade e compreendam as propostas metodológicas, é preciso repensar a forma de apresentar os gêneros acadêmicos.

\section{Referências Bibliográficas}

BAKHTIN, Mikhail. Estética da criação verbal. São Paulo: Editora WMF Martins Fontes, 2011.

BHATIA,V.K. Words of written discourse: a genre-based view.London: Continuum, 2004.

BEHLING, Janaina. Resumos de comunicação e o agenciamento da escrita científica. 2008. 126 p. Dissertação (mestrado) - Universidade Estadual de Campinas, Instituto de Estudos da Linguagem, Campinas, SP. Disponível em: http://www.repositorio.unicamp.br/handle/REPOSIP/269358. Acesso em: 14 fev. 2020 .

BIASI-RODRIGUES, B.; HEMAIS, B.; ARAÚJO, J. C. Análise de gêneros na abordagem de Swales: princípios teóricos e metodológicos. In: B. BIASI RODRIGUES; J. C. ARAÚJO; S.C. T. SOUSA (Org.). Gêneros textuais e comunidades discursivas: um Diálogo com John Swales. Belo Horizonte: Autêntica Editora, 2009. p.17-32.

BRASIL/UNILAB. VI Semana Universitária - Ciência e Diversidade de Gênero: produção de saberes para a afirmação dos direitos humanos. Universidade da Integração da Lusofonia Afrobrasileira. Redenção-Ce, 2019. Disponível em: http://semanauniversitaria.unilab.edu.br. Acesso em: 09 jul. 2020.

BRASIL/UNILAB. Projeto Pedagógico do Curso de Licenciatura em Física. Universidade da Integração da Lusofonia Afrobrasileira. Redenção, 2018. Disponível em: http://www.unilab.edu.br/wp-content/uploads/2018/11/PPCFÍSICA- NOVEMBRO-2018.pdf. Acesso em: 15.ago.2020. 
BRASIL/ UNILAB. Projeto Pedagógico do Curso de Licenciatura em Letras-Língua Portuguesa. Universidade da Integração da Lusofonia Afrobrasileira. Redenção-Ce, 2018a. Disponível em: http://www.letras.ihl.unilab.edu.br/wpcontent/uploads/2017/06/PPC-SEMESTRAL-LETRAS-Lingua-Portuguesa.pdf. Acesso em: 15.ago.2020.

BRUCHÊZ. Adriane et al. Metodologia de Pesquisa de Dissertações sobre Inovação: Análise Bibliométrica. XV Mostra de Iniciação Científica, PósGraduação, Pesquisa e Extensão. Programa de Pós-Graduação em Administração - Universidade de Caxias do Sul.

FERREIRA, Elisa Cristina Amorim. Fazer um resumo, mas como? Revista Ao Pé da Letra: Revista dos alunos da graduação em Letras, Recife, v. 131, n. 1, p. 118, 2011. Semestral. Disponível em: https://periodicos.ufpe.br/revistas/pedaletra/article/view/231774/25918. Acesso em: 09 mar. 2020.

FLORES, L. L; OLIMPIO, L. M. N; CANCELIER, N.L. Resumo. In: FLORES, L. L. Redação: o texto técnico/científico e o texto literário. Florianópolis: Ed. da UFSC, 1994, p.138 -158.

HYLAND, K. Disciplinary discourse: social interactions in academic writing.Singapura: Pearson Education Limited,2000.

MACHADO, Anna Rachel. Revisitando o conceito de resumos. In: Gêneros textuais e ensino. São Paulo: Parábola Editorial, 2010. p. 149-162.

MENESES, R. A. Produção de Abstracts no VIII Congresso de Iniciação Científica da UFCG: O que é requerido e o que é demonstrado? 2013. Monografia (Graduação em Letras - Língua Portuguesa) - Unidade Acadêmica de Letras, Universidade Federal de Campina Grande, Campina Grande, PB, 2013.

MOTTA-ROTH, Désirée. A importância do conceito de Gêneros discursivos no ensino da redação acadêmica. Intercâmbio, São Paulo, v. 8, p. 01-11, 1999. Disponível em: https://revistas.pucsp.br/index.php/intercambio/article/view/4029. Acesso em: 07 ago. 2020.

MOTTA-ROTH, Désirée. Análise crítica de gêneros: contribuições para o ensino e a pesquisa de linguagem. DELTA [online]. 2008, vol.24, n.2, pp.341-383. Disponível em: http://dx.doi.org/10.1590/S0102-44502008000200007. Acesso em: 22 ago. 2020.

MOTTA-ROTH, D.; HENDGES, G. R. Uma análise transdisciplinar do gênero abstract. Intercâmbio, São Paulo, v. 7, p. 117-25, 1998. Disponível em: http://coral.ufsm.br/labler/publi/anlise.htm. Acesso em: 20 mai.

2020.

MOTTA-ROTH, D.; HENDGES, G. R. Produção textual na universidade. São Paulo: Parábola, 2010. 
PEREIRA, Rodrigo Costa; RODRIGUES, Rosângela Hammes. Perspectivas atuais sobre gêneros do discurso no campo da Linguística. Letra Magna: Revista Eletrônica de Divulgação Científica em Língua Portuguesa, Linguística e Literatura, n. $11, \quad$ p. $1-18, \quad 2009 . \quad$ Disponível em: http://www.letramagna.com/generoslinguistica.pdf. Acesso em: 18 mai. 2020.

RABELO, Ana Paula. Os processos de letramentos nas transformações de identidades de três gerações de mulheres escolarizadas. 2017. 360f. - Tese (Doutorado) - Universidade Federal do Ceará, Programa de Pós-Graduação em Linguística, Fortaleza (CE), 2017.

SILVA, Marcos Paulo da; GUIZZO, Antonio Rediver. O Gênero Abstract: questões de compreensão e produção textual. In: FALE - Fórum Acadêmico de Letras, 28., 2017, Paraná. Anais [...]. Foz do Iguaçu: 2017. p. 1-4. Disponível em: https://dspace.unila.edu.br/bitstream/handle/123456789/3319/FALE_127130. pdf? sequence=1\&isAllowed=y. Acesso em: 14 abr.2020.

SWALES, J. Genre Analysis: English in academic and research settings. Cambridge: Cambridge University Press, 1990. 